\title{
Analysing the impact of COVID-19 on the mothers of Bangladesh: hearing the unheard
}

\author{
Shah Md. Azimul Ehsan ${ }^{1}$ (D) - Fairooz Jahan ${ }^{2}$ \\ Received: 2 September 2020 / Accepted: 23 February 2021 / Published online: 12 March 2021 \\ (C) The Author(s), under exclusive licence to Springer-Verlag GmbH Germany, part of Springer Nature 2021
}

\begin{abstract}
Aim The purpose of this empirical study was to understand, explore and analyse how the COVID-19 pandemic has affected the mothers of our society, with particular emphasis on Bangladesh, which has so far been a relatively unexplored area.

Subject and methods The study adopted qualitative and interpretative methods of social research, including content analysis and a perception study of 223 respondents through a semi-structured questionnaire survey, who were selected using purposive random sampling. The data obtained from the perception study was further complemented through phone interviews.

Results The study found that the pandemic has not affected all mothers uniformly; rather, the intensity of its impact varied depending on factors such as the occupation of mothers and their husbands and their family pattern. Despite such variation, all mothers experienced a subsequent increase in workload, challenges while availing routine health facilities and higher levels of stress, anxiety, depression and certain behavioural changes.

Conclusion However, the worst affected have been the mothers belonging to the lower socio-economic strata because the pandemic has made them and their husbands jobless, leading them towards an uncertain future.
\end{abstract}

Keywords Pandemic $\cdot$ Mothers $\cdot$ Workload $\cdot$ Covid-19 $\cdot$ Stress $\cdot$ Anxiety

\section{Introduction}

Mankind has stumbled into one of its greatest crisis since World War II over the past few months. With over $21,912,154$ cases and a death toll of more than 774,739 as of August 2020 (Worldometer 2020a), the world is indeed fathomlessly struggling with an epoch-making public health menace, COVID-19, which originated in Wuhan, China, in December 2019 (Ghosh et al. 2020). The incidence and mortality of the coronavirus-2019 disease (COVID-19) have been increasing dramatically worldwide (Fernandes 2020).

Shah Md. Azimul Ehsan

ehsan.azim@yahoo.com

Fairooz Jahan

fjahan2811@gmail.com

1 Department of Public Administration, Jagannath University, Dhaka, Bangladesh

2 Department of History, University of Dhaka, Dhaka, Bangladesh
Bangladesh, a country of South Asia, has also fallen a victim to this pandemic. To date, 279,144 people have tested positive for COVID-19 and the death toll has risen to 3694 (Worldometer 2020b).

The effects of the COVID-19 pandemic are not limited to health but also have a major impact on social and economic aspects. A global socio-economic deadlock has been created, which has propelled the lion's share of the population to home-confinement while the rest have been engaged rather selflessly in uneven mortal combat against it (Kickbusch et al. 2020). Reports of abuse, negligence, exploitation and domestic violence are on a horrendous rise during this COVID-19 pandemic and lockdown (New York Times 2020; UNICEF 2020). Meanwhile, developing and less developed countries are arguably experiencing a more severe crisis than developed countries, with many small and medium-sized businesses being disrupted and even bankrupt (Fernandes 2020). In addition, restraints related to the pandemic (e.g. social distancing, home quarantine, and isolation) are impacting on economic sustainability and wellbeing, which may induce psychological mediators, such as sadness, worry, fear, anger, annoyance, frustration, guilt, helplessness, loneliness and nervousness (Mamun and Griffiths 2020; Mukhtar 
2020). These mediators are also distinctive features of psychological suffering that individuals can experience during and after pandemics (Ahorsu et al. 2020; Bhuiyan et al. 2020; Pakpour and Griffiths 2020).

Since its outbreak, both scientists and social scientists have conducted many studies on COVID-19. From one end of the spectrum, the world has seen relentless, hair-splitting and scrupulous research by scientists for developing a vaccine and, very recently, there have been successful reports about Russia's breakthrough in discovering the vaccine for taming this deadly virus. Although the announcement was welcomed across the globe, it was not without skepticism as some scientists in Russia and other countries expressed concern over the vaccine's effectiveness and safety and so the hunt for a vaccine remains ongoing (Dhaka Tribune 2020). While on the other end of the spectrum, social scientists have conducted several studies to determine the socio-economic as well as the psychologial aspects of COVID-19 covering various topics involving livelihood, children, refugees, migrant workers, gender disparity, mingling with the new-normal, etc. For instance, Li et al. (2020), Wang et al. (2020), Huang and Zhao (2020), Vindegaard and Benros (2020) and Pappa et al. (2020) all studied the psychological impact of COVID19 in China and found that the pandemic has resulted in higher levels of depression, anxiety, stress, mental disorders and insomonia. Moreover, patients with pre-psychiatric disorders reported worsening of their symptoms. In addition, Dsouza et al. (2020) and Mamun and Ullah (2020) studied the COVID-19 suicide causative factors from the specific country context of India and Pakistan. The studies found that some of the prominent reasons which lead to extreme cases of suicide are fear of being infected by COVID-19, lockdown-related economic recession, loneliness, work-related stress because of COVID-19, social boycott and pressure being in quarantine, being COVID-19 positive, unable to return home due to lockdown, unavailability of alcohol, etc. Following the recent trend of global scholars, a few studies have been conducted in the context to Bangladesh in order to know the psychological impact and problems related to mental health emanating from COVID-19 in the Bangladesh population which include Islam et al. (2020), Mamun et al. (2020a, b, c, 2021). These studies had similar findings to other global COVID-19 studies in that the pandemic has caused higher levels of stress, depression and uncertainty in the people of Bangladesh. In extreme cases, many are considering the options of suicide (Mamun et al. 2020b, c).

Thus, it is evident that many studies have touched upon socioeconomic and psychological problems emanating from COVID-19. However, there remains a dearth of literature on how Covid-19 has affected mothers and expecting mothers. In other words, scholars have shown very limited interest on what impact COVID-19 has had and is still having on the mothers of our society. Roberton et al. (2020) rightly pointed out that as the global pandemic has had a negative impact on people of different ages and different professions, there is no doubt that mothers of different age groups and of various professions have also been affected in multifarious ways. The blessing of motherhood naturally also comes with an abundance of stress issues. Every woman who has been dealing with the natural hardships of regular life gains a lot of new challenges from having a child and throughout the whole period of raising the child. This natural phenomena of motherhood has been highly confronted by the pandemic as much as it has affected any other field. In addition to all other socio-political and economic dynamics, this particular issue should be thoroughly researched and needs to be brought to the world's attention so that women who are giving birth and raising children during this unprecedented time receive the recognition they deserve. Hence, this paper is an attempt to unearth the added hardship of mothers (with specific context to Bangladesh) caused by the pandemic which has been relatively an unexplored area to date. The study also aims to make their unheard voices reach both national and international academic discourses.

\section{Methodology}

This study is exploratory in nature and data was collected using qualitative and interpretative methods of social research. First, the researchers used content analysis methods where various academic articles, newspapers, reports, web portals, and other existing literature relevant to the research objective were thoroughly reviewed. This has helped the researchers to enrich their understanding of this topic. Second, a perception study was undertaken by the researchers using a semistructured survey questionnaire having both open ended and close ended questions. The survey questionnaire was designed so that necessary information related to the research objective can be obtained. For instance, the respondents were asked if they faced difficulty in the case of availing health facilities, what sort of impact COVID-19 had on their job sector, to what extent has their work load been increased due to the pandemic, were they getting support from their husbands and other family members, how they perceive the 'work from home' in the 'new normal' situation, has the pandemic increased their level of stress or anxiety, whether they faced the scenario of physical or verbal abuse/violence during the pandemic situation, etc. As mentioned earlier, the survey questionnaire was semi-structured, there were several probing questions to obtain more responses from the respondents. The findings were further complemented with phone interviews to obtain more insightful views from the respondents. The phone interview technique has also helped the authors to remove ambiguity of certain terms such as 'stress'. In the most generic form, 
stress is a feeling of emotional or physical tension, which often is generated from an event. However, stress can be quite relative based on perception of the individuals. Talking more with the respondents with empathy over the phone has further facilitated finding out quite interesting facts related to higher levels of anxiety and stress owing to COVID-19. The total sample size was 223. The respondents were selected using the purposive random sampling technique. The rationale behind using this sampling technique was to include mothers of various professions, age groups, family backgrounds and also to include a substantial number of expecting mothers. Such diversification has not only helped to enrich the findings but also unearthed different narratives from these unheard mothers.

\section{Synopsis of the respondents' profiles}

As previously mentioned, the total sample size for this study is 223. Before we move into discussion, it is important to give a synopsis of the respondents' profile which will clarify their diversification in terms of age, their occupation, occupation of their husbands and the type of family in which they reside. Most of the respondents (47\%) belonged to the age range of (29-33), while more than a quarter of respondents (27\%) belonged to the age range of (23-38). Very few respondents $(2 \%)$ and $(5 \%)$ belonged to age range (18-22) and (44-49), respectively. Approximately one third of the respondents $(36 \%)$ were homemakers, $10 \%$ were government service holders, $12 \%$ were teachers, $7 \%$ were bankers, $5 \%$ were businessperson, and $16 \%$ were engaged in some other profession such as garments sector, domestic work and students. The respondents' husbands were also from different professions such as teaching, government service, banking, medical sector, and business. Table 1 illustrates all this information.

\section{Negative impact on availing health facilities}

In past epidemics, health systems have struggled to maintain routine services and utilization of services has decreased
(Wilhelm and Helleringer 2019). As WHO notes, 'People, efforts, and medical supplies all shift to respond to the emergency. This often leads to the neglect of basic and regular essential health services. People with health problems unrelated to the epidemic find it harder to get access to health care services' (WHO 2018). A study of the 2014 epidemic of the Ebola virus disease estimated that, during the outbreak, antenatal care coverage decreased by 22 percentage points, and there were declines in the coverage of family planning ( 6 percentage points), facility delivery ( 8 percentage points), and postnatal care (13 percentage points) (Sochas et al. 2017; Abbas et al. 2020; Roberton et al. 2020). During the 2003 severe acute respiratory syndrome epidemic, ambulatory care decreased by $23.9 \%$ in Taiwan and inpatient care decreased by $35.2 \%$ (Chang et al. 2004). Simulated models of influenza pandemics also predict reductions in utilization of health services (Rust et al. 2009; Gilbert et al. 2020; Roberton et al. 2020).

Already with COVID-19, we are seeing similar disruptions. The pandemic and the response to the pandemic are affecting both the provision and utilization of reproductive, maternal, newborn, and child health (RMNCH) services. Amid the pandemic, health workers, equipment, and facilities have been reassigned to address the influx of patients with COVID-19 (Gilbert et al. 2020). Restructuring of the health system could result in the closure of peripheral health facilities, as seen in the 2014 Ebola virus outbreak (Brolin Ribacke et al. 2016; Gilbert et al. 2020).

Similar restructuring of all the available health facilities has been done in Bangladesh to combat the pandemic. The pandemic has tremendously disrupted sexual and reproductive health services for long-term and ultimately led to upsurge in unmet need for family planning, inappropriate contraception, unsafe abortion, unplanned pregnancy, increased rate of sexually transmitted infections, and overall a mal-functioning feto-maternal healthcare and reproductive health services (Hall et al. 2020). Approximately 92\% respondents agreed to the fact that Covid-19 has had a negative impact on their availability of routine health facilities (Fig. 1).

Table 1 Profile of the respondents

\begin{tabular}{|c|c|c|c|c|c|c|c|}
\hline \multirow[t]{2}{*}{ Age of the respondents } & Age range (18-22) & $\begin{array}{r}\text { Age range } \\
(23-28)\end{array}$ & $\begin{array}{r}\text { Age range } \\
(29-33)\end{array}$ & $\begin{array}{r}\text { Age range } \\
(34-38)\end{array}$ & $\begin{array}{r}\text { Age range } \\
(39-43)\end{array}$ & \multicolumn{2}{|c|}{ Age range (44-49) } \\
\hline & $2 \%$ & $27 \%$ & $46 \%$ & $12 \%$ & $8 \%$ & $5 \%$ & \\
\hline \multirow[t]{2}{*}{$\begin{array}{l}\text { Occupation of the } \\
\text { respondents }\end{array}$} & $\begin{array}{l}\text { Government } \\
\text { service }\end{array}$ & Doctor & Teacher & Banker & Businessperson & $\begin{array}{l}\text { Home } \\
\text { maker }\end{array}$ & Others \\
\hline & $10 \%$ & $12 \%$ & $14 \%$ & $7 \%$ & $5 \%$ & $36 \%$ & $16 \%$ \\
\hline \multirow{2}{*}{$\begin{array}{l}\text { Occupation of the } \\
\text { respondents } \\
\text { husbands }\end{array}$} & $\begin{array}{l}\text { Government } \\
\text { service }\end{array}$ & Doctor & Teacher & Business person & Banker & Others & \\
\hline & $16 \%$ & $7 \%$ & $8 \%$ & $20 \%$ & $8 \%$ & $41 \%$ & \\
\hline \multirow[t]{2}{*}{ Family type } & Joint family & & Nuclear family & & Extended family & & \\
\hline & $41 \%$ & & $56 \%$ & & $3 \%$ & & \\
\hline
\end{tabular}


More than one third of the respondents (approx. 40\%) felt COVID-19 has adverse effects on their family planning. When it comes to the prenatal and post-natal checkups of the expecting mothers and new mothers, COVID-19 again has severely disrupted these facilities. Almost $50 \%$ of the expected mothers and new mothers of the sample population strongly agreed that both their pre-natal and post-natal checkups were greatly affected, while nearly $39 \%$ percent of them were of the opinion that they were partially affected (Fig. 2). A research officer in the Bangladesh Insitute of Bank Management (BIBM) who became pregnant during the COVID-19 pandemic shared her gloomy experience with us. 'When there was sudden lockdown from $23 \mathrm{rd}$ March, the whole country came to a total deadlock. As I am pregnant, I have to go for frequent checkups. But my regular doctor's chamber was closed as she was posted elsewhere to address the pandemic crisis. The situation one day got so worst that I was bleeding and immediately needed to do sonology but could not find any sonlogist after roaming around 3-4 hospitals. I am very much concerned about the availability of doctor during my child birth'.

Another respondent who is a doctor by profession and recently gave birth to her daughter also suffered owing to the disruption of the regular health facilities. She had to plan caesarean delivery instead of waiting for normal delivery considering the uncertainty of the availability of the doctors. Now, she is facing problems with post-natal checkups. Availability of blood donors is very crucial during child birth. The COVID-19 pandemic has also created a fear factor as well as various obstacles for the donors to reach hospitals because of the stereotyped perception of hospitals being a hub of coronavirus. The Assistant Manager of Nuclear Power Plant Company Bangladesh faced a similar situation while giving birth to her child during the pandemic. In her words, 'My EDD (expected date of delivery) was on 14th April. I managed 3 blood donors for me. One of them left Dhaka in fear. Another one was stuck in Old Dhaka as he didn't have personal vehicle and the last one was afraid to come to hospital. Finally, I had to manage blood donor who walked in just before 45 minutes. We were very worried that nobody might make it to the hospital'.

Even after giving birth, mothers need medical assistance or follow-up which has been a crucial issue now. An anonymous new mother shared with us that even after giving birth six months ago, she still has not recovered fully from the 'episiotomy' wounds and still requires stitches. However, she is afraid to go to the hospital due to the pandemic. Besides the physical aspects, many mothers go through post-natal depression which also requires medical assistance. However, in our society, post-natal health care for mothers, especially psychological care, remains largely unacknowledged. The pandemic has made it even harder for these women to seek medical help for themselves.

Apart from their own health issues, many young mothers missed the regular vaccinations of their babies owing to country-wide lockdown. Although the immunization program has gradually resumed, the fear factor remains very high and many are reluctant to go to vaccination centres. Mothers have also complained about the unavailability of the child specialists and pediatricians during the lockdown period and even now, in certain cases, child specialists are very hard to come by. One of the respondents, whose husband is a driver by profession, expressed with grief, 'my daughter is just 3.5 years old has been suffering from hernia. I was advised by doctor to undergo operation when she grows up. However, last month, one night she was groaning in pain and we immediately rushed to Comilla Zilla hospital for doctor. We were rejected on the ground that doctors have been prescribed only to deal cases related to corona patients. Next morning, we took our daughter to several hospitals in Dhaka but the result was no different'.

Meanwhile, many doctors have opted for online treatment services. This has benefited the mothers of solvent and educated families who are now consulting doctors online and

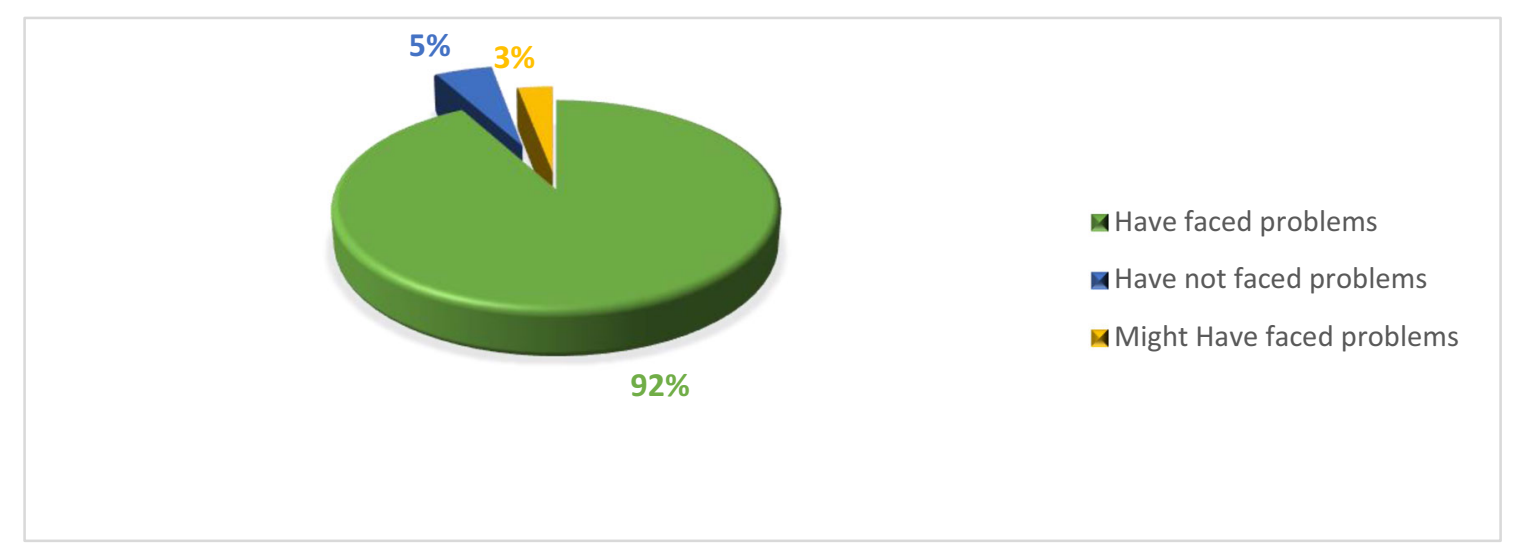

Fig. 1 Impact of COVID-19 on availing routine health facilities 
Fig. 2 Impact of COVID-19 on prenatal and post-natal checkups

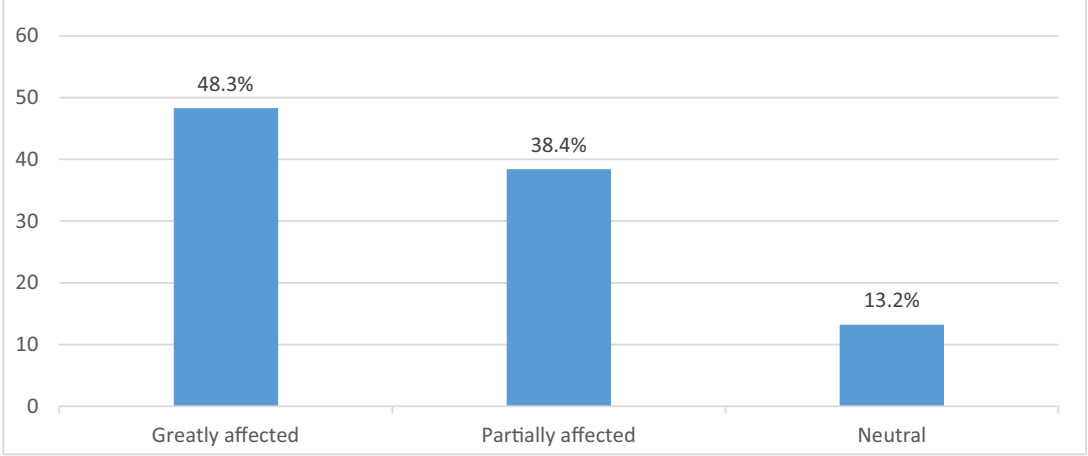

reaping the benefits of tele-medicine. However, this came as no real help for the mothers of poor and uneducated families because of the digital divide that exists in the country.

\section{Impact on job sector}

According to a report of ILO, approximately $40 \%$ of female workers, that is, 510 million females, have been affected badly due to the pandemic. The pandemic has devastated serviceoriented sectors that employ more women such as restaurants, hotels and hospitality, leading to more job losses (Miller 2020). In context to Bangladesh, the COVID-19 outbreak is already having a significant impact on small businesses, with shops, restaurants and beauty salons closed, and a limited number of restaurants doing delivery (UN Women 2020). More than two-thirds of the total working mothers in this study agreed that since the outbreak of COVID-19 in Bangladesh, their respective job sectors had been negatively impacted, although the intensity was great for $58 \%$ of the respondents (Fig. 3).

Many garments workers worldwide have lost their jobs due to the COVID-19 pandemic. However, reports suggest that women are losing jobs more than their male counterparts. For instance, one of the reputed national dailies of Bangladesh, Prothom Alo, reported the case of a female garment worker who worked in Taketex Fashion Limited for the past few years but was sacked without prior notice due to the pandemic (Rana 2020). This is just one of many similar cases that have been reported in various national dailies. Interestingly though, there have been reports of a few cases where working mothers voluntarily left the job to take care of the children and family without any helping hand because of the pandemic. The case of a non-government female journalist needs special mention here who had to voluntarily quit her job because someone has to stay home to take care of the family and children. Thus, experts fear that these women run a high risk of not regaining their lost job during the crisis situation. Concerns have also been raised if that happens, then all the limited development that has occurred regarding the gender equation worldwide will be lost (Haque 2020).

Apart from the contribution of women in the formal economy, nearly $60 \%$ of them around the world work in the informal economy, with low wages and less savings or safety nets. One of the professors of the University of Dhaka rightly

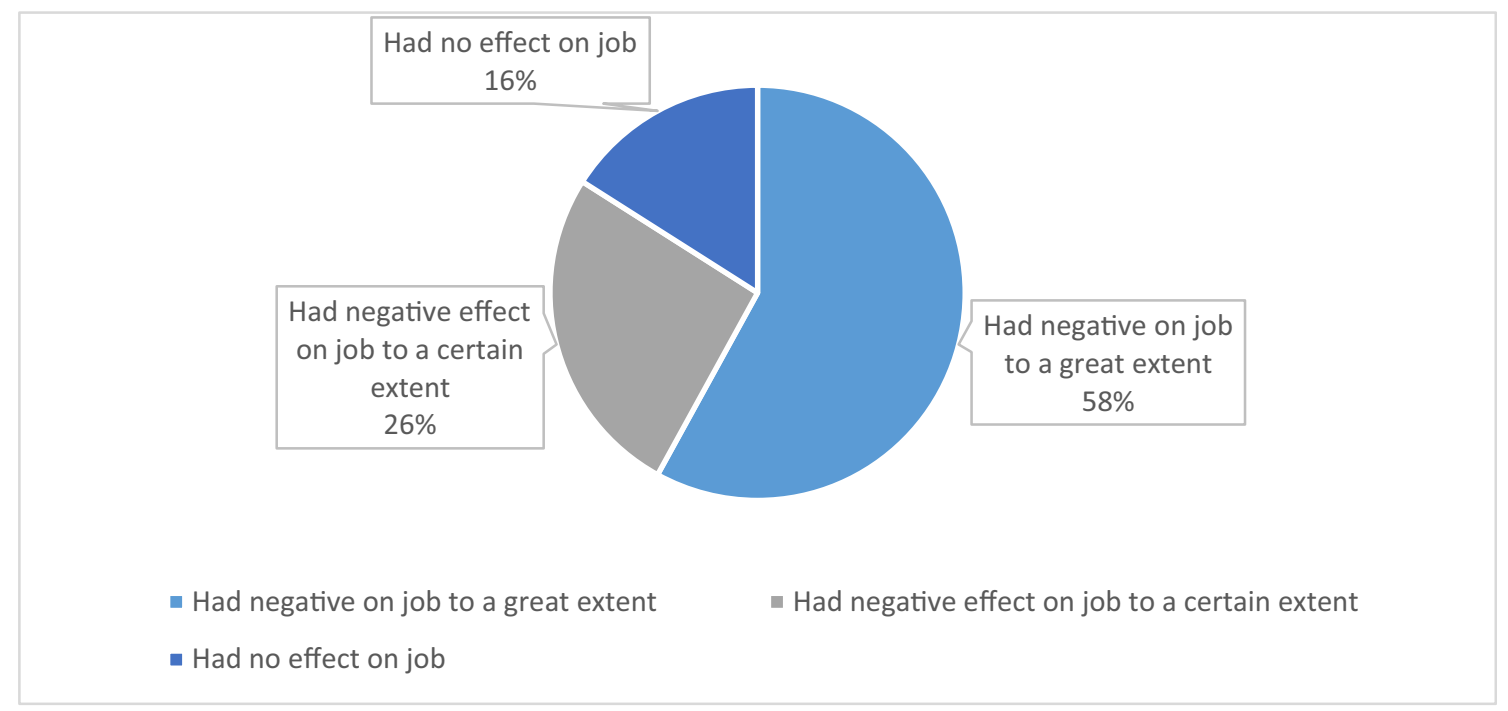

Fig. 3 Impact of COVID-19 on job sector of the respondents 
pointed out that during the COVID-19 pandemic, women working in informal sectors have been affected the most (Haque 2020). Again, the majority of domestic workers in Bangladesh are also women. To stop community transmission of COVID-19, Bangladeshi families who had domestic workers have also let them go. For many domestic workers, this translates to no income and no food (UN Women 2020). Three of the respondents in this study who worked as domestic workers lost their jobs since last March. During the entire lockdown period, their families had barely any support or income.

Online business now is a big platform for women to earn. Especially for women with children for whom it is hard to do corporate jobs, online businesses have become an alternative source of employment. Many have invested all their savings and taken this as their main occupation. Though the pandemic has created huge dependency on online businesses for daily necessities, it has equally decreased the business of luxury items such as jewellery, garments, and cosmetics. Some respondents who have been involved in entrepreneurism and online business are also suffering due to the pandemic. One of them said, "Many shipments which my clients have preordered months earlier are either stuck in customs or the shipment is getting delayed. Shipment charge has unexpectedly rocketed in the last few months which I have to bear from my pocket. Many customers are understanding and bearing with us in this period of uncertainty. Nevertheless, some are losing patience and canceling their orders and claiming their advance payments. I don't know how to repay them now when I am myself under severe financial crises." On the contrary, women involved in online catering businesses are doing better in the pandemic because many are preferring the online homemade food delivery option due to the workload, unavailability of helping hands, risk of transmission in restaurants, etc.

\section{Increase in workload}

In Bangladesh, as in the rest of the world, women are the primary caregivers of the young, infirm, and the elderly. According to one of the recent studies of Amin (2020), women spend considerably more time on domestic work, caregiving work in particular, than men. As the pandemic continues, this burden of caregiving is likely to increase disproportionately for women. A survey conducted by UN Women (2020) has also come up with similar results that lockdown and social distancing have resulted in an increased burden of unpaid work and household chores, with little to no shift in redistribution of domestic work as a result of the confinement.

School and daycare closures during the orders of home stay further exacerbated the burden of unpaid care work on women who absorb most of the additional work of caring for children. Zmarro, a professor at the University of Arkanas, rightly pointed out that, "Considering women already shouldered a greater burden for child care prior to the pandemic, it's unsurprising that the demands are now even greater," (Miller 2020). Although men are at home and sharing some responsibilities, women's household chores have not necessarily decreased (UN Women 2020). In addition to the care responsibilities, the directives about cleanliness and hygiene are also likely to intensify the workloads of women who are the ones implementing instructions on wiping down high touch surfaces, washing clothes, maintaining general hygiene as well as the creative management of dwindling resources to put food on the table as provisions dry up (Amin 2020).

A lion's share of the respondents (78.5\%) strongly concurred that their workload has increased since the outbreak of the coronavirus (See Fig. 4). As mentioned earlier, when the country-wide lockdown was declared, most of the families who hire domestic workers to do the household chores asked them to discontinue in order to save themselves from transmission. Thus, it meant that women (both working and non-working mothers) had to bear the additional responsibilities which were previously done by domestic workers. Life becomes even more difficult when a women is COVID-19 positive in these circumstances. For instance, one of the respondents who is a housewife and has survived the COVID-19 scare, stated that 'I have become sick more because of immense workload than COVID-19. My family is nuclear one and it totally depends on me. My little daughter cannot go a moment without me. I needed rest but was unable to do that.' While another respondent, a young mother who has now graduated from Dhaka University, stated that her whole family was infected but she was lucky enough to escape the ill-fate. However, she had to take the risk of caring for all of them owing to unavailability of any close relatives.

Meanwhile, $10.3 \%$ of the respondents opined that COVID19 has not had a significant impact in the increase of their workload. While $11 \%$ totally negated that there was no difference on the amount of work which they did before and after the outbreak of pandemic (Fig. 4). This complexity can be explained by two factors. Firstly, the family type in which they reside; secondly, the support of their husbands in sharing the workload. About two-thirds of the respondents acknowledged the fact that they have been receiving ample support from their husbands and family members (Fig. 5). In this case, mothers and expecting mothers who belong to joint families were much blessed.

For instance, one of the respondents (an MA student at the University of Dhaka and also a young mother) informed that she did not face the same experience similar to most other women whose workload has immensely increased in the pandemic. Rather, she has received adequate support from her mother-in-law.

Another sector where mothers' workload has increased is the online classes of their children. Almost all the children 


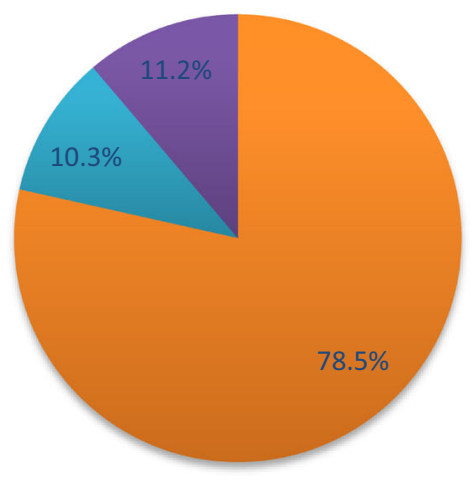

- Has added extra work load

- Has partially added extra extra workload

- Has not added extra work load

Fig. 4 Impact of COVID-19 on workload of the respondents

from kindergarten to secondary schools are now having online classes. While the grown up children can do that by their own, children of kindergarten and primary levels need assistance and that mostly comes from their mothers. One of the housewife mothers of the sample population stated that most often her 6 -ear-old boy falls asleep during the online classes and she is the one who continues on his behalf! For the housewife mothers, the added workload came with less acknowledgement than for the working mothers. As all the family members stayed home during the lockdown period, their workload has also increased many folds.

\section{Work from home: challenging or a blessing in disguise?}

Though the pandemic has made many working women jobless, it has added a new dimension for them as 'work from home'. Not every working woman who works in the formal sector fall within this classification. Women working as teachers, in research fields, government sectors and in certain non-government sectors had to adjust with this whole new concept of 'work from home'. Almost half of the total respondents (49\%) perceived it to be challenging, $44 \%$ had mixed feelings about it, while only $7 \%$ found it fascinating (Fig. 6). Why have so few respondents found it interesting to work from their own homes without the hassle of going out? The best possible answer to this query can be the nature of inertia. It is inherent nature of humans to continue the same old things which they were doing and most of them do not like changes because of uncertainty. However, this general explanation barely tells the inside story why most working mothers found work from home challenging. One of the Assistant Professors from the University of Dhaka asserted, 'there is a need to have a proper working environment for working which you cannot always find at home. We are expected to do the same job at home but reality is that I have to maintain my little son at one hand and also maintain the household chores at the other hand. And the post COVID-19 workload is a worrying factor too'.

However, another respondent who is also serving as an Assistant Professor at Jagannath University, Dhaka, had mixed feelings about the 'work from home' concept. She said, 'The reason I have mixed feelings is because I have found it both as blessing as well as challenging. I have a daughter who
Fig. 5 Support from husband and family members during pandemic

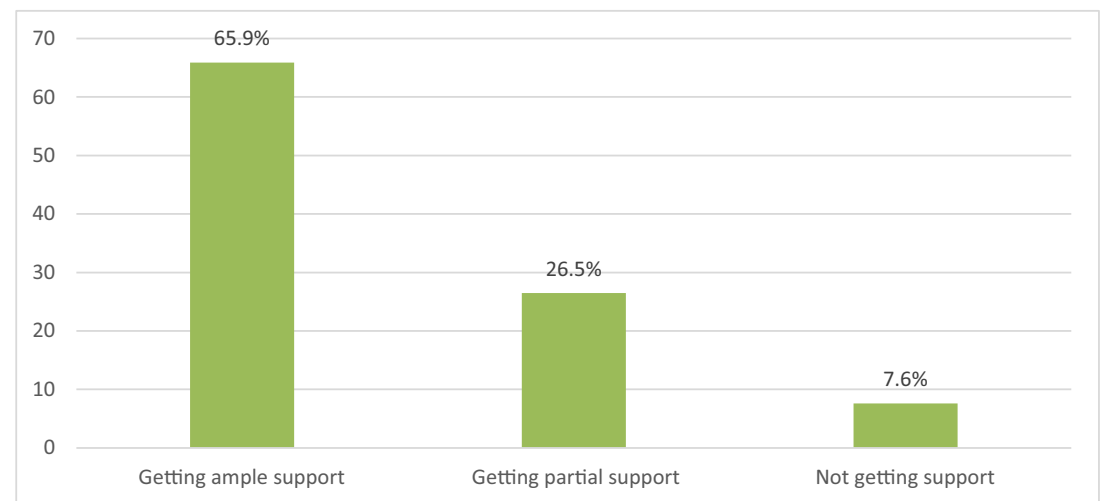




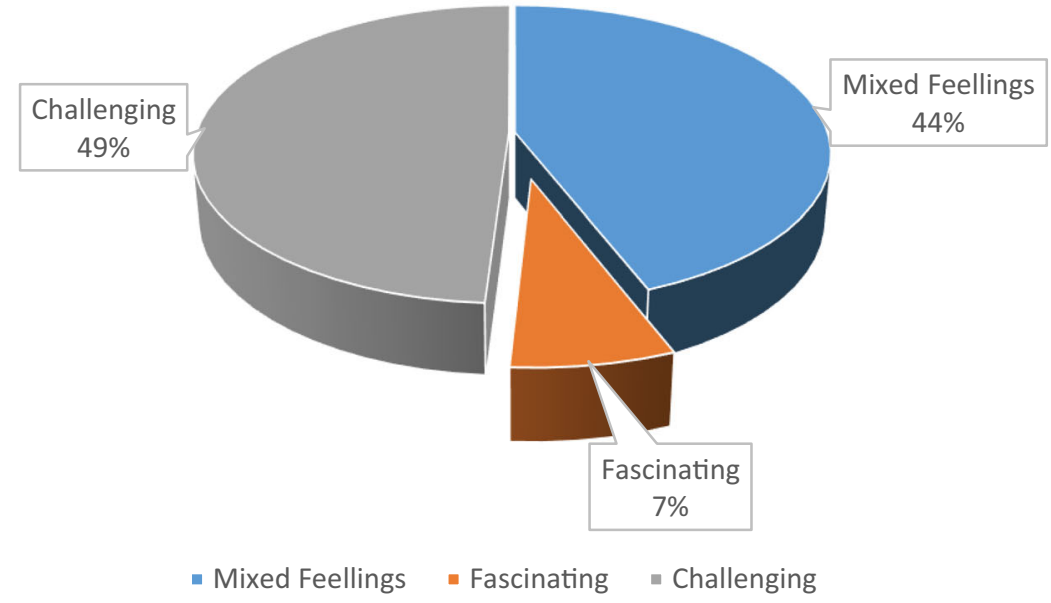

Fig. 6 Perception of working mothers regarding work from home

is 11 months old. I was in maternity leave for six months and joined University last January. I was so upset for my child when I had to rejoin my job but that's how life goes. I was praying if the leave could be extended! However, all the universities were closed under government directions from mid of March due to the pandemic. It came as an indirect blessing for me. Since then, I had been staying home with my daughter and have been able to spend more time with her which would not have been possible had the university was not closed. But then again, there is always other side of the coin as well. We were gradually advised to take online classes via Zoom and Google Classroom which is very alien to us. We were never accustomed to take classes online prior to this but we had to learn it and gradually got adapted. The most challenging part is that many of my family members don't understand that 'work from home' also requires same efforts! When I used to go to university physically for taking classes, they understood my workload. But now, as I am taking online classes from home, they have an assumption that perhaps that requires less effort than taking classes physically. Moreover, my daughter keeps on distracting me during classes and thus keeping concentration gets really difficult at times. On the other hand, my husband who is also in teaching profession, can conduct his online classes more smoothly'.

Albeit work from home has been broadly perceived as challenging and with mixed feelings by respondents, although a few respondents have found it rather fascinating. One of the respondents who is working in British Standard School stated 'taking classes online has been a huge blessing for me. I am expecting so it has lessen my anxiety about going to school physically for taking classes'.

Though for some academic mothers there is a privilege to schedule their classes according to their own convenient time, mothers in corporate fields and other jobs do not always have this luxury. The formal and timely meetings are often interrupted by the children or any other family member and distraction is common. The business owner and entrepreneur mothers are facing challenging times because their small shops or boutiques have been shut down. Not many of them have online platforms.

According to one survey of New York Times, it is the mother, not father, who has historically shouldered the vast majority of the childcare burden, and continued to do so during the pandemic. The COVID-19 pandemic has ushered in an era where parents, particularly women, are expected to achieve a perfect balance between work and childcare, and for basically the first time in human history, they are expected to do it on their own (Dickson 2020). Thus, many (40\% of the working mothers of the sample population) are struggling to strike a proper balance between new work lives, while $38 \%$ of the working mothers of the sample population felt that they were somewhat being able to cope with the family life and new work life brought on by the pandemic (Fig. 7).

However, all these challenges brought one blessing with them. The working mothers are now being able to spend more with their children which they have always dreamt of. Moreover they can also get some quality time with their partners who have also been home during the lockdown. The working mothers who breast-feed their children are seeing this as a great blessing. The homemaker mothers generally stay alone during the school and office hours. They are now having her full family together at home.

\section{Level of stress and anxiety of mothers during the COVID-19 pandemic}

From having a very competitive busy life to suddenly staying at home, stress and anxiety levels among people have increased many folds. Few earlier studies have investigated 
Fig. 7 Maintaining proper balance between work life and family life

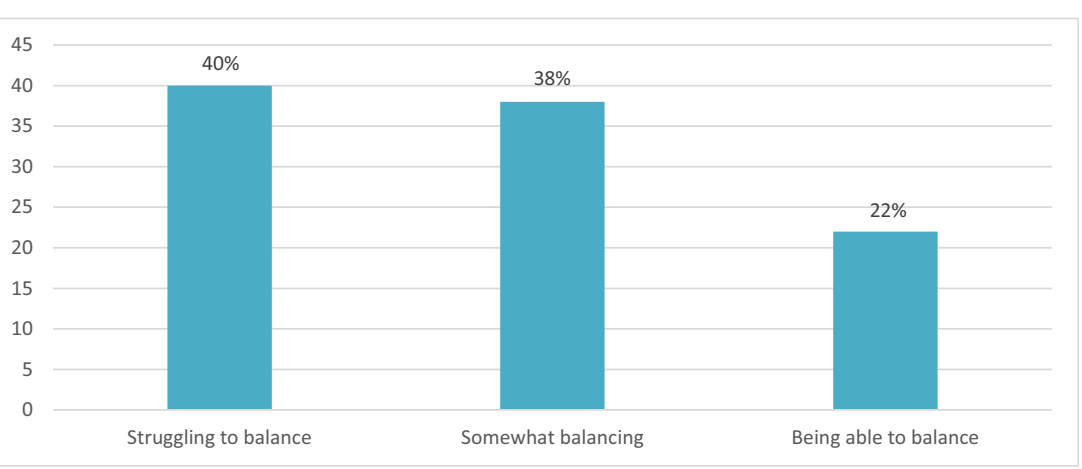

the impact of quarantine which was adopted in severe acute respiratory syndrome (SARS) and Middle-east respiratory syndrome (MERS) and reported high prevalence of psychological symptoms, which included depression, low mood, irritability, anxiety, stress and emotional disturbance (Hawryluck et al. 2004; Liu et al. 2012; Yoon et al. 2016). Similarly, analysis of the 2014 outbreak of the Ebola virus in West Africa showed that the indirect effects of the outbreak were more severe than the outbreak itself (Elston et al. 2017). It is very much obvious that women and children would be the most vulnerable section who would be facing similar psychological problems in the present pandemic (Spinelli et al. 2020). Almost all the respondents (98\%), agreed that their levels of stress and anxiety have increased since the outbreak of the coronavirus (Fig. 8). However, the factors behind the increased levels of stress and anxiety were not uniform for all respondents. Rather, variation was found across working and non-working mothers, professional differences, new and expecting mothers, and so on.

Because for a mother her children remain her prime concern, the stress level of mothers increased greatly during this pandemic centring on their child's health and wellbeing. As discussed earlier, most of them became stressed and anxious thinking whether it would be safe for them to take their child for vaccinations; what if they get infected; and again, if they were not given regular vaccinations, how much would that affect their babies; whether the essential items for babies such as formula milk, diapers, feeding bottles, clothes be available or not, whether pediatricians would be available for regular checkups; and when the world will get back to its previous state so that they can show the sunshine to their toddlers without fear of the coronavirus. The situation is worse in the case of pregnant mothers. Some of the prime reasons behind the stress and anxiety of the expecting mothers were whether the doctors would be available for regular checkups and at the time of child birth and emergency; what will happen if they get infected with coronavirus, whether their newborn be able to see this world. One of our respondent working at the Nuclear Power Plant Company Bangladesh Limited, shared her terrible experience, 'I went to labor on 13th April. We tried to hire car for emergency. Everybody refused to go to hospital. So, l had to take rickshaw and I had to walk from Uttara police station to Uttara Cresent Hospital with labor pain. It was horrible'. New mothers already have high chance to fall into post-natal depression. Thus, mothers who are giving birth during this pandemic have a higher probability of having postnatal depression due to the added stress of the present context.

Again, the factors which stressed working and nonworking mothers were different. Non-working mothers predominant reason for becoming stressed was the thought that

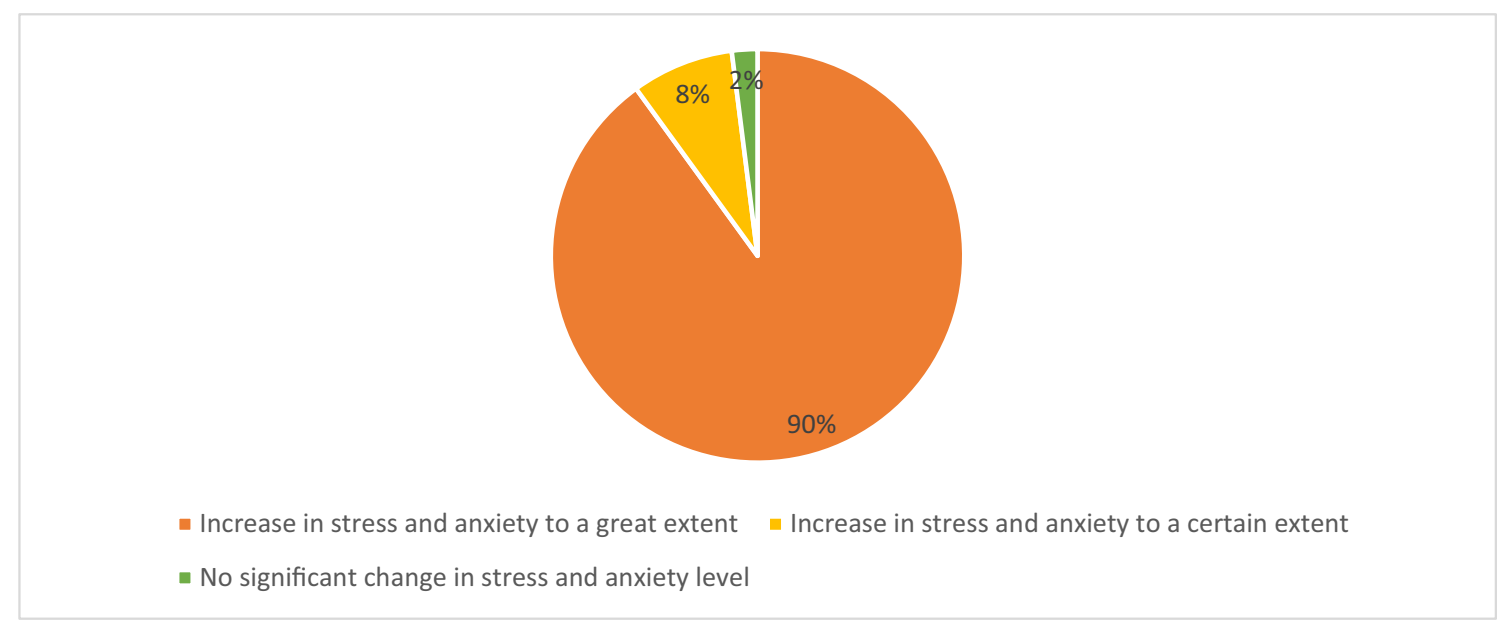

Fig. 8 Level of stress and anxiety of mothers during COVID-19 pandemic 
someday their husband might get infected and transmit the virus to their family. However, the rationales which caused higher level of anxiety and stress in working mothers were again diversified and it varied from one profession to another. Those who used to work on non-formal sectors such as garments and as domestic workers became stressed due to economic scarcity and uncertainty of rejoining their old jobs which they have left very recently.

The doctors, who are the frontline fighters against the pandemic, were found to be stressed thinking about their children and other family members being affected by them. One of the doctors whom we interviewed (working in Dhaka Medical College Triage department where COVID-19 patients are immediately brought after testing positive) stated, 'I am not worried for myself. I am seriously concerned for my children. What if I become a carrier and then they get infected? Will I be ever able to forgive myself for that?'. Moreover, another reason for a higher level of anxiety among doctor mothers was insufficient supply of masks and gloves and poor infrastructural facilities in the hospitals. For instance, one of the doctors working in Manikganj Upazila Health Complex stated, 'As an emergency doctor of Upazila (sub-district) Health Complex (UHC), I've to serve lot of patients including suspected COVID-19 ones. Many of them become positive after RT$P C R$ testing. But there is no sufficient infrastructure in our hospital premises to protect ourselves. There is no donning and doffing room, even there are not sufficient supply of good quality masks \& gloves. So, the biggest challenge is to protect ourselves from the virus as well as our children'.

Similar concerns were also raised by bankers who had to serve twice a week even in the midst of lockdown. The situation for government service holders is also similar. One Deptuty Secretary posted at the Defense Ministry informed us that even during the pandemic she had to travel to Faridpur district due to her job commitments. Her 12-yearold child was home with an elderly grandmother so she made sure she could come back within the same day from Faridpur during the pandemic.

Again, the reasons for stress for a mother who is raising her child alone and whose husband is a migrant worker is quite different to that of a single or divorcee mother, who are the sole provider for their children. Whereas the latter mother's reason for anxiety is thinking about the health status and job security of her husband, the former mother's principle reason of stress is how to manage both children and job properly as they neither have the supporting hand of their partner nor do they have the option to quit the job because of financial reasons. Furthermore, the divorcee mothers who do not have custody of their children had a yet different rationale for being anxious because the prolonged lockdown made them wait for a long time between meetings with their children.

Despite such variation in factors behind stress and anxiety, monetary stress had a rather significant impact on all the respondents. Many had their or their husband's salary reduced, in many cases. We found respondents who experienced salary cuts during the pandemic which led to higher levels of stress, anxiety and also depression. One of the respondents mentioned that her husband had a $27 \%$ salary cut due to the pandemic which affected them quite badly.

The end results of such high levels of stress and anxiety are different psychological behavioural changes such as rudeness, irritation, shouting with children, insomnia and becoming annoyed at little things. In extreme cases, few find no other alternative but to commit suicide. For instance, on 12 April, a woman and mother of five children (aged 35 years) from Cox's Bazar attempted suicide by hanging, although she was rescued by one of her sons. Her husband also lost his job during the pandemic. Despite that the government was providing relief for the poor, they did not receive any such funds. The mother could not bear to watch her children starving and thus attempted suicide thinking it could bring food for her family by gaining public attention (Bhuiyan et al. 2020; Campus Today 2020). Such cases have become a common phenomenon in the pandemic albeit national dailies and electronic media do not even report a quarter of those suicides. Additionally, the families also do not want the death of loved ones to be reported as suicide news in Bangladesh to avoid the suicide-related social and criminal complexities (Bhuiyan et al. 2020; Mamun et al. 2020a, b).

\section{The impact of violence against women on motherhood}

There have been reports that domestic violence had a horrendous rise at the time of COVID-19 pandemic and lockdown (New York Times 2020; UNICEF 2020). Particularly, anxieties over health, finance, partial inactivity of several welfare organizations due to lockdown and frustration encircling forced home-stay are factors behind this rapid soaring of domestic violence during the pandemic (Usher et al. 2020). In the context of Bangladesh, where there is already high prevalence of violence against women, the risk is clearly greater. This leads to the legitimate expectation that there would be stronger commitments towards mitigating these risks in our national response to COVID-19. However, in the nationallevel actions and strategies pursued so far to address the pandemic, there has been very little emphasis on the issue of gender-based violence, or so it seems from the publicly available information, reflecting a lack of concern at the policy level (Yasmin 2020).

According to a recent survey by the Manusher Jonno Foundation (MJF), a local human rights organization, at least 4249 women were subjected to domestic violence in 27 out of 64 districts of Bangladesh in April, with 1672 women facing violence for the first time in their lives. The survey further revealed that 848 women were abused physically and 2008 
were abused mentally by their husbands. Shaheen Anam, the executive director of MJF opined that the situation is similar in the other districts of Bangladesh as well. The women, who faced domestic violence for the first time, blame the lockdown for their situation. They said that their husbands are becoming increasingly frustrated at home due to a lack of social interaction. Arpita Das, a coordinator at the MJF stated that 'Men are angry about losing their jobs due to the COVID-19 lockdown. They cannot go out to meet friends. Some are venting their frustration by torturing their wives' (Islam 2020).

However, protesting emotional and physical violence remains uncommon in our society. When the respondents were asked if they had faced any such case of domestic violence in the form of physical, verbal or mental form, they totally denied it. Few respondents even gave reactions with frowned eyebrows which reflected how much social taboo remains about asking such a question in our society. Only two respondents, who did not gave their consent to disclose their identity, agreed that they were victims of domestic violence during the pandemic. One of the respondents who works as a domestic worker stated that 'My husband has been beating me since we got married. At times he used to beat me so much that I could not go to my workplace. Now, in the pandemic he isn't earning much. Hence he is beating me more. I have accepted it as fate. We poor women have no right to complain.' The domestic worker women became more vulnerable after losing their earning source during the pandemic. The effect of such violence on children is immense. Women facing violence, often vent out their anger on their children. Moreover the children who are seeing such violence against their mothers are growing up with terrible mental scars.

\section{Has the pandemic made the lives of mothers totally gloomy?}

There is no denying the fact that the pandemic has so far had relatively high socio-economic and psychological costs regarding most women, and mothers in particular, but it is not a totally grey area. Modernization is literally compelling parents in rat racing at the opportunity cost of spending quality time with their children. However, the country-wide lockdown to contain the transmission of the coronavirus turned out to be a golden opportunity for these deprived children who were able to spend abundant time with their parents. Home education from parents and endearment are sine qua non for positive growth of a child (Ghosh et al. 2020). Work from home has also been a great booster for working mothers. Some respondents said that they have used the period of lockdown and quarantine days for developing their skills, particularly in IT, doing IT courses. Many are learning baking and developing cooking skills. Some women along with their motherhood, also came forward to social development works. The case of executive director of 'Obhijan', a non- governmental organization (NGO), needs a special mention here. She went to visit her in-laws house in Jessore last March when the country-wide lockdown was declared. Rather than panicking and getting distressed, she worked out what she could do to use all her past experience of 10 years in the field of development. She formed a cooperative of women named 'Olkapuri', and its main purpose was to create awareness among the village people 'Egarokhan' regarding the coronavirus. They showed the villagers how to wash their hands properly and disinfect objects using detergents. These women of the newly formed cooperative under her leadership and guidance also created a blockade with bamboo so that people from other village might not enter into their place. Moreover, the teenage girls who belong to the 'Yellow gang' of this cooperative have cut crops in the fields because hiring day laborers in the midst of the pandemic was becoming very much taxing for the village farmers. Furthermore, the women of the cooperative arranged a village fair every Saturday where goods produced by the members of the cooperative were on display for use by the village people free of cost. Her cooperative is doing wonders in that village, and to date, no case of a COVID-19 patient has been reported. She rightly said, 'There is no point in sitting idle saying coronavirus has come. Yes it has arrived and we have to adapt to the new normal' (Hossain 2020).

\section{Concluding remarks}

The pandemic has so greatly affected the world that researchers from different corners are analysing the socioeconomic and political scenario to predict the aftermath. However, amid this, a large community has been almost left out. Though many are working on the impact of the pandemic on women, there is not much empirical work on how this twenty-first century pandemic has affected mothers in particular. Hence, this paper sought to portray the unheard voices of Bangladeshi mothers. The findings of this study have revealed that the impact of the coronavirus on Bangladeshi mothers has not been a uniform one; rather, variations were reflected in the case of the social hierarchy of mothers. Whereas the anxiety for mothers of the solvent class is the fear of their family getting infected by the virus, the fear of the insolvent working class mother is to keep her family fed. To most of the slum dweller mothers, this global pandemic is just a 'rich man's disease' and their foremost enemy is hunger. The study further found that where the stress owing to the ongoing pandemic in upper class mothers leads to various psychological problems such as depression, insomnia and behavioural changes, the stress resulted in suicide or suicide attempts in extreme cases for mothers belonging to the lower strata due to the fiscal crisis. 
Nevertheless, the bridge that connects the mothers of both these classes is the sense of fear; fear to lose their child and their family. Another interesting finding that this study has unearthed is related to physical and emotional violence between the mothers of these two classes. It is a common phenomenon for women belonging to the lower strata to speak out about their husbands' violent behaviour to other women of their class. However, when it comes to the mothers of the upper strata who faced violence in their family during the pandemic, they hesitate to bring those to light due to the fear of losing so-called social image. Though the Bangladesh government is taking many measures to secure the nation from the clutches of this deadly pandemic, it has relatively remained silent in securing the women from violence.

If we consider the broader area, in every national or international crisis period, women are the most affected in both personal and public life. The condition of mothers in Bangladesh - in fact, worldwide - is no different right now. Besides violence, loss of career and increase in workload, these factors with the already existing hurdles of motherhood and proper balance of personal and professional lives have made the pandemic even worse for mothers. This study has shown many cases where, even if the mother is a COVID-19 positive patient, she has to take care of the house. Again, if any other family member is affected, she also has to take care of them without fearing the contamination chances. The World Health Organization (WHO), government and health experts have been suggesting that isolation is the best measure for COVID-19 patients, but have not answered the question of how mothers who are the sole-career of their families health and hygiene can maintain this isolation policy if they are required to do so; and if they do, who would take care of their family? Perhaps, social scientists and policymakers are still pondering answers to these questions. Mothers have no rest, not even in the pandemic, and that is where their strength lies.

Despite so many negativities which the pandemic has brought for most mothers, the study also found that it has worked as an indirect blessing for a certain portion. The country-wide lockdown and closure of schools provided them the opportunity to spend quality time with their children and family members that has helped to strengthen their bonds. Again, a few mothers used the time to develop their skills or work on their passions. However, the pandemic did not bring any indirect blessing for mothers from lower socio-economic strata. Rather, financial crisis, the struggle to feed their family, along with the fear to survive this critical period, added more tolls on them, and their lives have become more miserable, challenging and very stressful. It remains unknown exactly how the workload or stress of these mothers can be lessened. The least that can be done is letting the world hear their unheard stories and narratives and, accordingly, acknowledge their contributions.

The significant strength of this study lies in the nature of it methodology. In other words, being qualitative in nature and relying on the interpretative methods, this study has brought the very raw and unheard narratives of the respondents which are often ignored by quantitative studies. However, the limitation of this study is its heavy reliance on qualitative research tools and non-adoption of any quantitative tools of social research. It needs to be mentioned here that use of statistical tools was beyond the scope of this study. Nonetheless, it is expected that this particular study, along with contributing to the existing literature, will encourage other researchers to conduct further studies on this relevant topic using either crosstabulations or combining both qualitative and quantitative methods.

Acknowledgements The authors acknowledge the effort given by every respondent mother who spent their precious time participating in the questionnaire survey and phone interview to provide their insights that have helped to furnish data for this paper.

Funding This study was conducted with self-finance and the authors declare that this study was not sponsored by any donors or research based organizations.

Declarations The authors declare that while conducting this study and in preparing this paper, they have complied with all ethical standards.

Informed consent Informed consent was obtained from all individual participants included in the study.

Conflict of interest The authors declare that they have no conflict of interest that are relevant to the content of this article.

\section{References}

Abbas K, Procter S, van Zandvoort K et al (2020) Routine childhood immunization during the COVID-19 pandemic in Africa: a benefit-risk analysis of health benefits versus excess risk of SARS-CoV-2 infection. Lancet Glob Health. https://doi.org/10. 1016/S2214-109X(20)30308-9

Ahorsu DK, Lin C-Y, Imani V, Saffari M, Griffiths MD, Pakpour AH (2020) The fear of COVID-19 scale: development and initial validation. Int J Ment Heal Addict. https://doi.org/10.1007/s11469-02000270-8

Amin S (2020) Bangladeshi women play crucial role in fight against Covid-19. Brac Institute of Governance \& Development (BIGD) https://bigd.bracu.ac.bd/bangladeshi-women-play-crucial-role-infight-against-covid19/?fbclid=IwAR1203q56ZNnx5hBrtYWyo 5W6FwcqKkUIQXRSgMf9pkU2mX6pwjd0pOs3pI. Accessed 26 Aug 2020

Bhuiyan AKMI, Sakib N, Pakpour AH et al (2020) COVID-19 related suicides in Bangladesh due to lockdown and economic factors: case study evidence from media reports. Int J Ment Heal Addict. https:// doi.org/10.1007/s11469-020-00307-y

Brolin Ribacke KJ, Saulnier DD, Eriksson A, von Schreeb J (2016) Effects of the West Africa Ebola virus disease on health-care utilization-a systematic review. Front Public Health 4:222. https://doi.org/10.3389/fpubh.2016.00222

Campus Today (2020) Mothers' suicide attempt due to children starving (In Bangla). https://bit.ly/2VSSv0F. Accessed 26 Aug 2020 
Chang HJ, Huang N, Lee CH, Hsu YJ, Hsieh CJ, Chou YJ (2004) The impact of the SARS epidemic on the utilization of medical services: SARS and the fear of SARS. Am J Public Health 94(4):562-564. https://doi.org/10.2105/ajph.94.4.562

Dhaka Tribune (2020) WHO in talks with Russia on Covid-19 vaccine. Dhaka. https://www.dhakatribune.com/world/europe/2020/08/12/ who-in-talks-with-russia-on-covid-19-vaccine. Accessed 26 Aug 2020

Dickson EJ (2020) Coronavirus Is killing the working mother. Rolling Stone. https://www.rollingstone.com/culture/culture-features/ working-motherhood-covid-19-coronavirus-1023609/. Accessed 26 Aug 2020

Dsouza DD, Quadros S, Hyderabadwala ZJ, Mamun MA (2020) Aggregated COVID-19 suicide incidences in India: fear of COVID-19 infection is the prominent causative factor. Psychiatry Res 290:113145. https://doi.org/10.1016/j.psychres.2020.113145

Elston JWT, Cartwright C, Ndumbi P, Wright J (2017) The health impact of the 2014-15 Ebola outbreak. Public Health 143:60-70. https:// doi.org/10.1016/j.puhe.2016.10.020

Fernandes N (2020) Economic effects of coronavirus outbreak (COVID19) on the world economy, IESE Business school working paper No. WP-1240. https://doi.org/10.2139/ssrn.3557504. Accessed 26 Aug 2020

Ghosh R, Dubey MJ, Chatterjee S, Dubey S (2020) Impact of COVID-19 on children: special focus on the psychosocial aspect. Minerva Pediatr 72:226-235. https://doi.org/10.23736/S0026-4946.20. 05887-9

Gilbert M, Pullano G, Pinotti F et al (2020) Preparedness and vulnerability of African countries against importations of COVID-19: a modelling study. Lancet 395(10227):871-877. https://doi.org/10. 1016/S0140-6736(20)30411-6

Hall KS, Samari G, Garbers S et al (2020) Centring sexual and reproductive health and justice in the global COVID-19 response. Lancet 395(10231):1175-1177. https://doi.org/10.1016/S0140-6736(20) $30801-1$

Haque S (2020) Uncertainty regarding return of women in their jobs (In Bangla). Prothom Alo https://bit.ly/3a8WvCX. Accessed 26 Aug 2020

Hawryluck L, Gold WL, Robinson S, Pogorski S, Galea S, Styra R (2004) SARS control and psychological effects of quarantine, Toronto, Canada. Emerg Infect Dis 10(7):1206-1212. https://doi. org/10.3201/eid1007.030703

Hossain M (2020) No point in sitting idly saying corona corona (In bangla) Prothom Alo. https://bit.ly/37WKKgw. Accessed 26 Aug 2020

Huang Y, Zhao N (2020) Generalized anxiety disorder, depressive symptoms and sleep quality during COVID-19 outbreak in China: a webbased cross-sectional survey. Psychiatry Res 12:112954. https://doi. org/10.1016/j.psychres.2020.112954

Islam A (2020) COVID-19 lockdown increases domestic violence in Bangladesh. https://p.dw.com/p/3c6lv. Accessed 26 Aug 2020

Islam SD, Doza MB, Khan RM, Haque MA, Mamun MA (2020) Exploring COVID-19 stress and its factors in Bangladesh: a perception-based study. Heliyon 6(7):e04399. https://doi.org/10. 1016/j.heliyon.2020.e04399

Kickbusch I, Leung GM, Bhutta ZA, Matsoso MP, Ihekweazu C, Abbasi $\mathrm{K}$ (2020) Covid-19: how a virus is turning the world upside down. BMJ 369:m1336. https://doi.org/10.1136/bmj.m1336

Li S, Wang Y, Xue J, Zhao N, Zhu T (2020) The impact of COVID-19 epidemic declaration on psychological consequences: a study on active Weibo users. Int J Environ Res Public Health 17(6):2032. https://doi.org/10.3390/ijerph17062032

Liu X, Kakade M, Fuller CJ, Fan B, Fang Y, Kong J, Guan Z, Wu P (2012) Depression after exposure to stressful events: lessons learned from the severe acute respiratory syndrome epidemic. Compr Psychiatry 53(1): $15-23$
Mamun MA, Griffiths MD (2020) First COVID-19 suicide case in Bangladesh due to fear of COVID-19 and xenophobia: possible suicide prevention strategies. Asian J Psychiatr 51:102073. https:// doi.org/10.1016/j.ajp.2020.102073

Mamun MA, Ullah I (2020) COVID-19 suicides in Pakistan, dying off not COVID-19 fear but poverty?-the forthcoming economic challenges for a developing country. Brain Behav Immun 87:163-166. https://doi.org/10.1016/j.bbi.2020.05.028

Mamun MA, Akter T, Zohra F, Sakib N, Bhuiyan AKMI, Banik PC, Muhit M (2020a) Prevalence and risk factors of COVID-19 suicidal behavior in Bangladeshi population: are healthcare professionals at greater risk? Heliyon 6:e05259. https://doi.org/10.1016/j.heliyon. 2020.e05259

Mamun MA, Chandrima RM, Griffiths MD (2020b) Mother and son suicide pact due to COVID-19-related online learning issues in Bangladesh: an unusual case report. Int J Ment Heal Addict 7:1-4. https://doi.org/10.1007/s11469-020-00362-5

Mamun MA, Doza MB, Griffiths MD (2020c) Hospital suicide due to non-treatment by healthcare staff fearing COVID-19 infection in Bangladesh? Asian J Psychiatr 54:102295. https://doi.org/10.1016/ j.ajp.2020.102295

Mamun MA et al (2021) The COVID-19 pandemic and serious psychological consequences in Bangladesh: a population-based nationwide study. J Affect Disord 279:462-472. https://doi.org/10.1016/j.jad. 2020.10 .036

Miller J (2020) COVID-19 has hit women hard, especially working mothers. Business Health. https://news.usc.edu/171617/covid-19women-job-losses-childcare-mental-health-usc-study/. Accessed 26 Aug 2020

Mukhtar MS (2020) Mental health and psychosocial aspects of coronavirus outbreak in Pakistan: psychological intervention for public mental health crisis. Asian J Psychiatr 51:102069. https://doi.org/ 10.1016/j.ajp.2020.102069

New York Times (2020) A new Covid-19 crisis: domestic abuse rises worldwide. https://www.nytimes.com/2020/04/06/world/ coronavirusdomestic-violence.html. Accessed 26 Aug 2020

Pakpour AH, Griffiths MD (2020) The fear of Covid-19 and its role in preventive behaviors. J Concurr Disord 2(1):58-63 http://irep.ntu. ac.uk/id/eprint/39561/

Pappa S, Ntella V, Giannakas T, Giannakoulis VG, Papoutsi E, Katsaounou P (2020) Prevalence of depression, anxiety, and insomnia among healthcare workers during the COVID-19 pandemic: a systematic review and meta-analysis. Brain Behav Immun. https:// doi.org/10.1016/j.bbi.2020.05.026. Advance online publication

Rana M (2020) 10,000 garments workers fired in 6 months: industrial police. Prothom Alo (in Bangla). https://bit.ly/2LpDstS. Accessed 26 Aug 2020

Roberton T, Carter ED, Chou VB, Stegmuller AR, Jackson BD, Tam Y, Sawadogo-Lewis T, Walker N (2020) Early estimates of the indirect effects of the COVID-19 pandemic on maternal and child mortality in low-income and middle-income countries: a modelling study. Lancet Glob Health 8(7):E901-E908. https://doi.org/10.1016/ S2214-109X(20)30229-1

Rust G, Melbourne M, Truman BI, Daniels E, Fry-Johnson Y, Curtin T (2009) Role of the primary care safety net in pandemic influenza. Am J Public Health 99(Suppl 2):S316-S323. https://doi.org/10. 2105/AJPH.2009.161125

Sochas L, Channon AA, Nam S (2017) Counting indirect crisis-related deaths in the context of a low-resilience health system: the case of maternal and neonatal health during the Ebola epidemic in Sierra Leone. Health Policy Plan 32(suppl 3):32-39. https://doi.org/10. 1093/heapol/czx108

Spinelli M, Lionetti F, Pastore M, Fasolo M (2020) Parents' stress and Children's psychological problems in families facing the COVID19 outbreak in Italy. Front Psychol 11:1713. https://doi.org/10.3389/ fpsyg.2020.01713 
UN Women (2020) Far from the spotlight, women workers are among the hardest hit by COVID-19 in Bangladesh. UN Women. https://bit.ly/ 3 mhfuO8. Accessed 26 Aug 2020

UNICEF (2020) COVID-19: Children at heightened risk of abuse, neglect, exploitation and violence amidst intensifying containment measures. https://www.unicef.org/press-releases/covid-19childrenheightened-risk-abuse-neglect-exploitation-andviolenceamidst. Accessed 26 Aug 2020

Usher K, Bhullar N, Durkin J, Gyamfi N, Jackson D (2020) Family violence and COVID-19: increased vulnerability and reduced options for support. Int J Ment Health Nurs 29(4):549-552. https://doi. org/10.1111/inm.12735

Vindegaard N, Benros ME (2020) COVID-19 pandemic and mental health consequences: systematic review of the current evidence. Brain Behav Immun. https://doi.org/10.1016/j.bbi.2020.05.048

Wang C, Pan R, Wan X, Tan Y, Xu L, Ho CS, Ho RC (2020) Immediate psychological responses and associated factors during the initial stage of the 2019 coronavirus disease (COVID-19) epidemic among the general population in China. Int J Environ Res Public Health 17(5):1729. https://doi.org/10.3390/ijerph17051729

WHO (2018) Managing epidemics: key facts about major deadly diseases. https:/www.who.int/emergencies/diseases/managingep idemics/en/. Accessed 26 Aug 2020

Wilhelm JA, Helleringer S (2019) Utilization of non-Ebola health care services during Ebola outbreaks: a systematic review and meta- analysis. J Glob Health 9:010406. https://doi.org/10.7189/jogh.09. 010406

Worldometer (2020a) Coronavirus update (Live): 24,114,382 cases and 824,742 deaths from COVID-19 virus pandemic. Worldometers. info. https://www.worldometers.info/coronavirus/? Accessed 26 Aug 2020

Worldometer (2020b) Bangladesh coronavirus: 302,147 cases and 4,082 deaths - Worldometers.info. https://www.worldometers.info/ coronavirus/country/bangladesh/. Accessed 26 Aug 2020

Yasmin T (2020) Violence against women during Covid-19: accepting the threat as 'real' is paramount. The Daily Star. https://www. thedailystar.net/opinion/news/violence-against-women-duringcovid-19-accepting-the-threat-real-paramount-1935633. Accessed 26 Aug 2020

Yoon MK, Kim SY, Ko HS, Lee MS (2016) System effectiveness of detection, brief intervention and refer to treatment for the people with post-traumatic emotional distress by MERS: a case report of community-based proactive intervention in South Korea. Int J Ment Heal Syst 10:51. https://doi.org/10.1186/s13033-016-0083-5

Publisher's Note Springer Nature remains neutral with regard to jurisdictional claims in published maps and institutional affiliations. 